đánh giá sự phục hồi lại khả năng chơi thể thao cũng như sinh hoạt của bệnh nhân theo các mức độ từ chuyên nghiêp đến bán chuyên nghiệp, chơi thể thao giải trí hay chỉ là sinh hoạt lao động bình thường. Việc đánh giá này quan trọng vì nó cho thấy bệnh nhân sau phẫu thuật có thực sự trở lại được các hoạt động như trước kia hay không chứ không chỉ đơn thuần là đánh giá các hoạt động chức năng của khớp gối có bình thường hay không.

Trong nghiên cứu của chúng tôi, đánh giá theo thang điểm Tegner đối với 48 bệnh nhân được phẫu thuật cắt tạo hình sưn chêm, có 35 bệnh nhân có khả năng chơi thể thao, lao động như trước phẫu thuật chiếm $72,9 \%$ và 13 bệnh nhân không phục hồi được khả năng chơi thể thao, lao động như trước phẫu thuật.Wojciech W. nghiên cứu trên 157 bệnh nhân tổn thương sụn chêm trong 20 năm cho kết quả chỉ $70 \%$ số bệnh nhân đạt lại được mức hoạt động thể thao và sinh hoạt lao động như trước chấn thương.

\section{KẾT LUẬN}

- Ngày nằm viện trung bình 4,12 ( $\pm 1,07$ ngày)

- Điểm đau VAS sau mố trung bình 1,81 $( \pm 1,045)$

- Đánh giá theo thang điểm Lysholm, kết quả rất tốt và tốt đạt $89,6 \%$; kêt quả vừa đạt 10,4\%; không có kêt quả xấu.

- Kết quả tốt và rất tốt chiếm tỉ lệ cao ở bệnh nhân dưới 35 tuổi $(62,5 \%)$

-Nhóm bệnh nhân có kết rất tốt chủ yễu gặp ở những bệnh nhân được phẫu thuật trước 3 tháng $(58,1 \%)$, và 3-6 tháng $(32,3 \%)$.

- Tỷ lệ bệnh nhân rách sừng trước sụn chêm đạt kết quả rất tốt cao hơn tỷ lệ bệnh nhân rách sừng sau sụn chêm.

-Nhóm bệnh nhân rách sụn chêm theo hình thái rách dọc đạt kết quả rất tốt chiếm tỷ lệ cao nhất 85\%.

- Đánh giá khả năng phục hồi chơi thể thao theo thang điểm Tegner, tỷ lệ bệnh nhân có khả năng chơi thể thao, lao động như trước phẫu thuật chiếm 72,9\%.

\section{TÀI LIẸU THAM KHẢO}

1. AHen F. Anderson, Robert B. Snyder, and A. Brant Lipscomb. Anterior Cruciate Ligament Reconstruction: A Prospective Randomized Study of Three Surgical Methods. The American Journal of Sports Medicine, 2001; Vol.29, No.3: 272-279.

2. Lê Thanh Tùng. Đánh giá kết quả phẫu thuật nôi soi điều trị rách sụn chêm khớp gối do chấn thương tại bệnh viện $Y$ học thể thao. Luận văn chuyên khoa cấp 2 đại hoc Y Hà Nội, 2009.35 -60.

3. Nguyễn Quốc Dũng và công sự.' Kết quả phấu thuật cắt môt phần sun chểm khớp gối qua nội soi. Y học Việt Nam số đặc biệt,2003; 69-74.

4. Hoàng Mạnh Linh. Đánh giá kết quả điều trị thương tổn sụn chêm do chấn thương bằng phẩu thuật nội soi tại bệnh viện Việt Đức. Luận văn thạc sỹ, Trường Đại học Y Hà Nội. 2011.

5. Nguyễn Trân Quang Sáng. Kết quả điều trị tổn thương đồng thời hai sụn chêm khớp gối qua nội soi. Luânn văn thạc sỹ, Đại học Y Hà Nội.2016.

6. Gillquist Jan, Oretorp Nils. Arthroscopy Partial Meniscectomy-technique and longtearm resuulis. Clin Orthop, 1982; 167, 29-23.

7. Lysholm J. Gillquist. The evaluation of the knee ligament surgery with special emphasis to the use of a knee scoring scale. AmJSport Med, In press.1982.

8. Trịnh Đức Thọ, Phạm Ngọc Nhữ và cộng sự. Nhận xét điều trị tổn thương sụn chêm khớp gối qua 35 trường hợp phấu thuật nội soi. Y học Việt Nam số đặc biệt,2003; 296-299.

\title{
THAY ĐỔI CẢM GIÁC THƯỜNG GĂP CỦA NGƯỜI NGHIÊNN CHÍCH MA TÚY: HIẾU QUẢ TƯ CAN THIỆP CộNG ĐÔNNG NGẪU NHIÊN CÓ ĐỐI CHỨNG TẠI TỈNH PHÚ THỌ NĂM 2015-2017
}

\author{
Lê Mạnh Hùng1, Phạm Đức Mạnh¹, Nguyễn Anh Tuấn², \\ Nguyễn Hà Lầm $^{3}$, Nguyễn Hữu Thắng ${ }^{3}$
}

\section{TÓM TẮT}

${ }^{1}$ Cuc phòng chống HIV/AIDS, Bô Y tế, Hà Nội

2Viện vệ sinh Dịch tễ Trung Ương, Hà Nội

${ }^{3}$ Trường Đai hoc Y Hà Nội

Chịu trách nhiệm chính: Lê Mạnh Hùng

Email: manhhunglevaac@gmail.com

Ngày nhận bài: 23.2.2021

Ngày phản biên khoa hoc: 30.3.2021

Ngày duyệt bài: 7.4.2021
Mục tiêu: Đánh giá hiệu quả can thiệp về cảm giác thường gặp khi muốn thay đổi của người NCMT sau 12 tháng can thiêp. Đối tượng và phương pháp: Nghiên cứu can thiệp cộng đổng thực hiện trên 450 người nghiện chích ma túy (NCMT) từ 18 tuổi trở lên tại 30 xã/phường tỉnh Phú Thọ. Kết quả: Can thiệp có tác động đến cảm giác thường có của người NCMT, 9/17 cảm giác thường có của người NCMT có sự khác biệt về CSHQ giữa nhóm can thiệp và nhóm đối chứng. Can thiệp có tác động lên hầu hết các khía cạnh tâm trạng thường gặp của người NCMT khi muốn 
thay đổi $(p<0,05)$ ngoại trừ gây ra các vấn đề khi tìm kiếm/duy trì việc làm, làm cuộc sống trở nên tồi tệ và có thể dẫn đến cái chết. Kết luận: Can thiệp chưa tác đông manh mẽ trong viêc cải thiên cảm giác thường gặp và các cảm giác thường có khi muốn thay đổi của người NCMT, hiệu quả can thiệp chưa cao.

Tư khóa: Hiệu quả can thiệp, cảm giác, người nghiện chích ma túy.

\section{SUMMARY \\ CHANGING THE FEELING REGULARLY OCCUR OF INJECTING DRUG USERS: THE EFFICIENCY OF THE COMMUNITY INTERVENTION STUDY IN PHU THO, 2015-2017}

Objective: To evaluate the effectiveness of the intervention on common senses and common feelings when the injecting drug users (IDUs) want to change after 12 months. Subjects and methods: A randomized controlled trial of a community intervention was conducted on 450 IDUs aged 18 years and over in 30 commune health centers (CHCs) in Phu Tho. Results: The intervention study impacted on the common feelings of IDUs, 9/17 common feelings had differences in effective intervention between the experimental group and control group. Intervention study affects almost feelings of IDUs when they want to change $(p<0.05)$ except finding/maintaining a job, making life become bad and leading to death. Conclusions: This intervention study did not have a strong impact on improving feelings regularly occur of IDUs and its effective intervention was not high.

Keywords: Effective intervention, feeling, injecting drug users.

\section{I. ĐĂT VẤN ĐỀ}

Tại Việt Nam, dịch HIV/AIDS tiếp tục có xu hướng giảm nhưng chưa bền vững và có nguy cơ bùng phát cao nên không được can thiệp và kiểm soát manh mẽ [1]. Theo số liệu báo cáo của Cục Phòng, chống HIV/AIDS, tính đến ngày 31/10/2019, Việt Nam hiện có 211.981 người nhiễm HIV còn sống, 103.426 người nhiễm HIV đã tử vong, trong đó số người mới phát hiện nhiễm HIV chủ yếu từ 16-39 tuổi $(73,9 \%)$ [1].

Theo Báo cáo Đánh giá hiệu quả của chương trình điều trị nghiện các chất thuốc phiện bằng Methadone tại Hải Phòng và TP. Hồ Chí Minh (2014) cho thấy đối tượng tham gia nghiên cứu thường gặp phải tình trạng khó tập trung hoặc khó nhớ (51,19\%); trâm cảm/vô vọng (44,87\%); lo âu, căng thẳng nghiêm trọng $(32,26 \%) ;$ mất hứng thú nghiêm trọng $(29,91 \%)$. Ngoài ra đối tượng còn thường xuất hiện các cảm giác khác như khó kiểm soát hành vi bạo lực, ảo giác, có ý định tự tử hoắc cố gắng tư tử. Sau 24 tháng can thiêp, sức khỏe thể chất, sức khỏe tình thân và chất lượng cuộc sống được cải thiện đáng kể [2]. Nghiên cứu của tác giả Trân Xuân Bách trên người nhiễm HIV/AIDS tại Việt Nam (2018) cho thấy, đối tượng có nguy cơ trầm cảm do bị chê trách vì tình trạng sức khỏe và xấu hổ vì tình trang sức khỏe của mình $(p<0,05)$ [3].

Tuy nhiên, những nghiên cứu về những cảm giác thường gặp phải của người NCMT trước và trong thời gian can thiệp và đánh giá hiệu quả can thiệp về cảm xúc của đối tượng còn hạn chế. Vì vâyy chúng tôi tiến hành đánh giá hiệu quả can thiệp thiệp cộng đồng ngẫu nhiên có đối chứng lên các cảm giác thường gặp và các cảm giác thường có khi muốn thay đổi của người NCMT tại tỉnh Phú Thọ giai đoạn 2015-2017.

\section{II. ĐỐI TƯỢNG VÀ PHƯƠNG PHÁP NGHIÊN CỨU}

2.1. Đối tượng nghiên cứu. Người NCMT từ đủ 18 tuổi trở lên đã và đang tiêm chích ma túy trên địa bàn xã/phường được lựa chọn vào nghiên cứu.

2.2. Địa điểm và thời gian nghiên cứu. Nghiên cứu được tiến hành tại 30 xã/phường của tỉnh Phú Tho từ tháng 4/2015 đến tháng 12/2017.

2.3. Thiết kế nghiên cứu. Nghiên cứu can thiệp cộng đồng ngẩu nhiên có đối chứng được thực hiện trên nhóm CBYT, sau đó tiến hành đánh giá và so sánh hiệu quả can thiêp sau 12 tháng trên nhóm đối tượng NCMT tại địa phương.

Phương pháp nghiên cứu: định lượng.

2.4. Cỡ mẫu nghiên cứu

$$
n=Z_{1-\alpha / 2}^{2} \frac{1-p}{(\varepsilon p)^{2}}
$$

Trong đó: n: là số đối tượng nghiện ma túy cần điêu tra.

p: Tỷ lệ người NCMT tại tỉnh Phú Thọ tuân thủ điều trị thay thế chất gây nghiện bằng Methadone trong 1 năm tham gia điêu trị. Lấy $p=85,3 \%$ theo nghiên cứu của tác giả Nguyễn

Thị Thắm tại Hải Phòng năm 2014-2016 [4].

$\varepsilon$ : Mức sai lêch mong muốn. Chọ $\varepsilon=0,05$.

a: Mức ý nghĩa thống kê lựa chọn $a=0,05$.

Giá trị $Z$ thu được từ bảng $Z$ ứng với giá trị a $=0,05$ là 1,96 .

Cõ mẫu theo công thức là 338 người NCMT. Trước can thiêp: phỏng vấn được 236 người NCMT trong nhóm can thiệp và 214 người NCMT nhóm đối chứng. Kết thúc 12 tháng sau can thiêp, phỏng vấn được 201 đối tượng ở nhóm can thiêpp và 191 đối tượng ở nhóm đối chứng.

2.5. Phương pháp chọn mẫu. Tiến hành chọn ngẫu nhiên 30 xã/phường đảm bảo số lượng người NCMT từ 18 tuổi trở lên có thể tham gia nghiên cứu trong số các xã/phường đủ tiêu chuẩn. Dựa vào danh sách 30 xã/phường đã chọn, sử dụng phân mềm phân bố ngẫu nhiên 
để hạn chế yếu tố nhiễu và chọn ra 15 xã can thiệp và 15 xã đối chứng.

Thông tin tuyển chọn đối tượng được giới thiệu miệng và tờ rơi dán tại nhà vắn hóa thôn/xóm và TYT xã/phường. Khoảng 15 người NCMT sẽ được lựa chọn từ mỗi xã/phường tham gia nghiên cứu theo phương pháp chọn mẫu thuân tiên.

\subsection{Biến số nghiên cứu}

\section{Các nhóm biến số/chỉ số}

- Thông tin chung của người NCMT: giới, tuổi, dân tộc, tình trạng hôn nhân, trình độ học vấn, công việc, con cái, khả năng tài chính.

- Đánh giá hiệu quả can thiệp về những cảm giác thường có của người NCMT.

- Đánh giá hiệu quả can thiệp về những cảm giác thường gặp của người NCMT khi muốn thay đổi.

\subsection{Phương pháp thu thâap thông tin}

Mô hình can thiệp gồm 3 giai đoạn: Xây dựng chương trình can thiêp, Can thiệp thử nghiệm và can thiệp ngẫu nhiên có đối chứng. Đánh giá sẽ được hòn thành sau mỗi 3,6 và 12 tháng. Đối tượng sẽ được cán bộ nghiên cứu liên lạc, nhắc lại thời gian và địa điểm đánh giá. Can thiệp cộng đồng ngẫu nhiên có đối chứng thực hiện trên nhóm CBYT xã/phường và kết quả đầu ra của can thiệp sẽ được người NCMT đánh giá theo bộ công cụ đã thiết kế.

2.8. Xử lý và phân tích số liệu. Các phiếu điều tra được làm sạch, nhập liệu bằng phần mềm Epidata 3.1 (nhập liêu 2 lần và kiểm tra chéo) và phân tích bằng phần mềm SPSS 20.0.

Đánh giá hiệu quả can thiệp dựa vào chỉ số hiệu quả can thiệp (CSHQ). Các tỷ lệ được tính theo công thức:

$$
\operatorname{CSHQ}(\text { can thiệp })=\frac{\left|\mathrm{Pt}_{\mathrm{t}}-\mathrm{P}_{\mathrm{s}}\right|}{\mathrm{Pt}_{\mathrm{t}}}
$$

Trong đó: $\mathrm{CSHQ}$ là chỉ số hiệu quả; $\mathrm{P}_{\mathrm{t}}$ là tỷ lệ $\%$ trước can thiệp; Ps là tỷ lệ \% sau can thiệp.

Khi đó hiệu quả can thiệp bằng: $\mathrm{HQCT}=$ CSHQ \% can thiệp - CSHQ \% đối chứng

Sử dụng test kiểm định $X^{2}$ để kiểm định sự khác biệt về CSHQ của nhóm can thiệp và nhóm đối chứng. Sự khác biệt có ý nghĩa thống kê với $\mathrm{p}<0,05$.

2.9. Đạo đức nghiên cứu. Nghiên cứu được sự đồng ý của chính quyền và các cơ quan y tế tỉnh Phú Thọ, đối tượng tham gia nghiên cứu tự nguyện tham gia nghiên cứu, các thông tin được bảo mật, chỉ phục vụ cho mục đích nghiên cứu. Nghiên cứu được phê duyệt tại Viện Vệ sinh dịch tể Trung Ương ngày 20/9/2012 với mã số 16/HĐĐ.

\section{KẾT QUẢ NGHIÊN CỨU}

Trước can thiệp có 450 người NCMT đủ điều kiện và đồng ý tham gia nghiên cứu. Đối tượng có tuổi trung bình là $37,6 \pm 7,9$ (tuổi), hầu là nam giới đã lập gia đình hoặc đang chung sống với

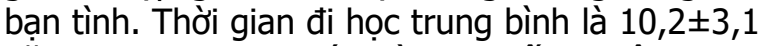
năm, tương đương với thời gian tốt nghiệp trung hoc cơ sở.

Hơn 3/4 người NCMT có công việc làm thêm gồm công việc toàn thời gian $(59,8 \%)$ hoặc bán thời gian (40,2\%). Trong số những người NCMT có công việc chiếm $26 \%$ người NCMT là công nhân, $24 \%$ là nông dân và $23,8 \%$ làm việc trong lĩnh vực dịch vụ.

Bảng 1. Hiệu quả can thiệp về những cảm giác thường có của người NCMT (\%)

Trước can thiệp: phỏng vấn được 236 người NCMT trong nhóm can thiệp và 214 người NCMT nhóm đối chứng. Kết thúc 12 tháng sau can thiệp, phỏng vấn được 201 đối tượng ở nhóm can thiệp và 191 đối tượng ở nhóm đối chứng.

\begin{tabular}{|c|c|c|c|c|c|c|c|c|}
\hline \multirow{2}{*}{ Nội dung } & \multicolumn{2}{|c|}{$\begin{array}{c}\text { Nhóm CT } \\
\text { Số lượng (\%) } \\
\end{array}$} & \multicolumn{2}{|c|}{$\begin{array}{c}\text { Nhóm ĐC } \\
\text { Số lượng (\%) } \\
\end{array}$} & \multirow{2}{*}{$\begin{array}{l}\text { CSHQ } \\
\text { CT } \\
(\%)\end{array}$} & \multirow{2}{*}{$\begin{array}{l}\text { CSHQ } \\
\text { ĐC } \\
(\%)\end{array}$} & \multirow{2}{*}{$\begin{array}{l}\text { HQCT } \\
\%\end{array}$} & \multirow{2}{*}{$\begin{array}{c}\text { p- } \\
\text { value }\end{array}$} \\
\hline & $\begin{array}{c}\text { TCT } \\
(n=236)\end{array}$ & $\begin{array}{c}\text { SCT } \\
(n=201)\end{array}$ & $\begin{array}{c}\text { TCT } \\
(n=214)\end{array}$ & $\begin{array}{c}\text { SCT } \\
(n=191)\end{array}$ & & & & \\
\hline $\begin{array}{c}\text { Mọi người săn lòng chấp } \\
\text { nhận }\end{array}$ & $55(27,4)$ & $17(8,5)$ & $47(24,6)$ & $9(4,7)$ & 69,0 & 80,9 & 11,9 & 0,15 \\
\hline $\begin{array}{c}\text { Moi người cho rằng người } \\
\text { sử dưng ma túy cũng có } \\
\text { thể đáng tin cây }\end{array}$ & $43(21,4)$ & $16(8,0)$ & $47(24,6)$ & $8(4,2)$ & 62,6 & 82,9 & 20,3 & 0,01 \\
\hline $\begin{array}{l}\text { Moi người chấp nhận một } \\
\text { người sử dụng ma túy là } \\
\text { giáo viên trong }\end{array}$ & $22(10,9)$ & $6(3,0)$ & $26(13,6)$ & $7(3,7)$ & 72,5 & 72,8 & 0,3 & 0,97 \\
\hline $\begin{array}{l}\text { Thuê một người có sử } \\
\text { dụng ma túy để chăm sód } \\
\text { con cái }\end{array}$ & $17(8,5)$ & $3(1,5)$ & $15(7,9)$ & $3(1,6)$ & 82,4 & 79,7 & 2,6 & 0,78 \\
\hline Đánh giá thấp người sử & $143(71,1)$ & $169(84,1)$ & $142(74,3)$ & $153(80,1)$ & 18,3 & 7,8 & 10,5 & $<0,01$ \\
\hline
\end{tabular}


VIETNAM MEDICAL JOURNAL N02 - APRIL - 2021

\begin{tabular}{|c|c|c|c|c|c|c|c|c|}
\hline \multicolumn{9}{|l|}{ dụng ma túy } \\
\hline $\begin{array}{l}\text { Thuê một người có sư } \\
\text { dụng ma túy nếu đủ năr } \\
\text { lực }\end{array}$ & $\begin{array}{c}51 \\
(25,4)\end{array}$ & $\begin{array}{c}24 \\
(11,9)\end{array}$ & $\begin{array}{c}49 \\
(25,7)\end{array}$ & $\begin{array}{c}24 \\
(12,6)\end{array}$ & 53,1 & 51,0 & 2,2 & 0,66 \\
\hline $\begin{array}{c}\begin{array}{c}\text { Sẽ không thuê người st } \\
\text { dụng ma túy }\end{array} \\
\end{array}$ & $\begin{array}{c}134 \\
(66,7)\end{array}$ & $\begin{array}{c}179 \\
(89,1)\end{array}$ & $\begin{array}{c}138 \\
(72,3)\end{array}$ & $\begin{array}{c}178 \\
(93,2)\end{array}$ & 33,6 & 28,9 & 4,7 & 0,06 \\
\hline $\begin{array}{l}\text { Săn sàng hên hò với má } \\
\text { người có sử dụng ma tú }\end{array}$ & $\begin{array}{c}35 \\
(17,4) \\
\end{array}$ & $\begin{array}{c}12 \\
(6,0)\end{array}$ & $\begin{array}{c}32 \\
(16,8)\end{array}$ & $\begin{array}{c}14 \\
(7,3)\end{array}$ & 65,5 & 56,5 & 9,0 & 0,13 \\
\hline $\begin{array}{c}\text { Đang bị cái xấu trừng } \\
\text { phat }\end{array}$ & $\begin{array}{c}137 \\
(68,2)\end{array}$ & $\begin{array}{c}156 \\
(77,6)\end{array}$ & $\begin{array}{c}131 \\
(68,6)\end{array}$ & $\begin{array}{c}144 \\
(75,4)\end{array}$ & 13,8 & 9,9 & 3,9 & $<0,01$ \\
\hline Cuộc sống đã bị hủy ho & $137(68,2)$ & $131(65,2)$ & $126(66,0)$ & $131(68,6)$ & 4,4 & 3,9 & 0,5 & 0,09 \\
\hline $\begin{array}{l}\text { Tức giận với bản thân } \\
\text { đã sứ dung ma túy }\end{array}$ & $\begin{array}{c}183 \\
(91,0)\end{array}$ & $\begin{array}{c}180 \\
(89,6)\end{array}$ & $\begin{array}{c}165 \\
(86,4)\end{array}$ & $\begin{array}{c}174 \\
(91,1)\end{array}$ & 1,5 & 5,4 & 3,9 & $<0,01$ \\
\hline $\begin{array}{c}\text { Là sự ghét bỏ đối với x } \\
\text { hội }\end{array}$ & $\begin{array}{c}114 \\
(56,7)\end{array}$ & $\begin{array}{c}124 \\
(61,7)\end{array}$ & $\begin{array}{c}106 \\
(55,5)\end{array}$ & $\begin{array}{c}128 \\
(67,0)\end{array}$ & 44,1 & 20,7 & 23,4 & $<0,01$ \\
\hline Cuộc sống đầy sự xấu h & $140(69,7)$ & ) $135(67,2)$ & $125(65,4)$ & $132(69,1)$ & 3,6 & 5,7 & 2,1 & $<0,01$ \\
\hline Thấy tội lồi & $174(86,6)$ & $176(87,6)$ & $172(90,1)$ & $178(93,2)$ & & & & \\
\hline $\begin{array}{c}\text { Thấy cuốc sống không } \\
\text { có ý nghĩa }\end{array}$ & $\begin{array}{c}77 \\
(38,3)\end{array}$ & $\begin{array}{c}38 \\
(18,9)\end{array}$ & $\begin{array}{c}87 \\
(45,5)\end{array}$ & $\begin{array}{c}47 \\
(24,6)\end{array}$ & 50,7 & 45,9 & 4,7 & 0,26 \\
\hline Mất danh tiếng/tự trọn & $161(80,1)$ & $166(82,6)$ & $152(79,6)$ & $169(88,5)$ & 3,1 & 11,2 & 8,1 & $<0,01$ \\
\hline $\begin{array}{l}\text { Muốn giấu việc sứ dụn } \\
\text { ma túy suốt cuộc đời }\end{array}$ & $\begin{array}{c}87 \\
(43,3)\end{array}$ & $\begin{array}{c}101 \\
(50,2)\end{array}$ & $\begin{array}{c}87 \\
(45,5)\end{array}$ & $\begin{array}{c}106 \\
(55,5)\end{array}$ & 15,9 & 22,0 & 6,0 & $<0,01$ \\
\hline \multicolumn{9}{|c|}{ 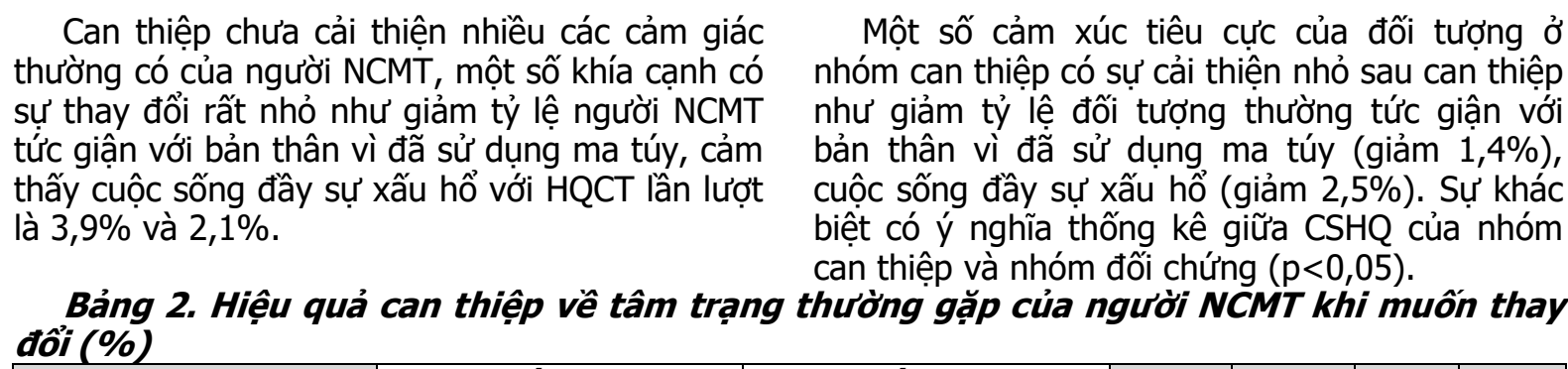 } \\
\hline \multirow[b]{2}{*}{ Nội dung } & \multicolumn{2}{|c|}{$\begin{array}{c}\text { Nhóm CT } \\
\text { Số lượng (\%) } \\
\end{array}$} & \multicolumn{2}{|c|}{\begin{tabular}{|c|} 
Nhóm ĐC \\
Số lượng (\%) \\
\end{tabular}} & \multirow{2}{*}{$\begin{array}{l}\text { CSHQ } \\
\text { CT } \\
(\%)\end{array}$} & \multirow{2}{*}{$\begin{array}{l}\text { CSHQ } \\
\text { ĐC } \\
(\%)\end{array}$} & \multirow{2}{*}{$\begin{array}{c}\text { HQC } \\
\mathbf{T} \\
\%\end{array}$} & \multirow{2}{*}{$\begin{array}{c}\text { p- } \\
\text { value }\end{array}$} \\
\hline & $\begin{array}{c}\text { TCT } \\
n=236)\end{array}$ & $\begin{array}{c}\text { SCT } \\
(n=201)\end{array}$ & $\begin{array}{c}\text { TCT } \\
(n=214)\end{array}$ & $\begin{array}{c}\text { SCT } \\
(n=191)\end{array}$ & & & & \\
\hline $\begin{array}{l}\text { Việc sử dụng ma túy } \\
\text { cúa ban là môtt vấn đề }\end{array}$ & $40(69,7)$ & $166(82,6)$ & $145(75,9)$ & $164(85,9)$ & 18,5 & 13,2 & 5,3 & $<0,01$ \\
\hline Cần sự giúp đõ & $67(83,1)$ & $184(91,5)$ & $163(85,3)$ & $176(92,1)$ & 10,1 & 8,0 & 2,1 & $<0,01$ \\
\hline $\begin{array}{l}\text { Gây ra các vấn đề đối } \\
\text { với pháp luật }\end{array}$ & $\begin{array}{c}184 \\
(91,5)\end{array}$ & $\begin{array}{c}181 \\
(90,0)\end{array}$ & $\begin{array}{c}165 \\
(86,4)\end{array}$ & $\begin{array}{c}172 \\
(90,1) \\
\end{array}$ & 1,6 & 4,3 & 2,6 & $<0,01$ \\
\hline $\begin{array}{c}\text { Gây ra các vấn đề khi } \\
\text { suy nghî và thực hiện } \\
\text { công việc }\end{array}$ & $\begin{array}{c}176 \\
(87,6)\end{array}$ & $\begin{array}{c}183 \\
(91,0)\end{array}$ & $\begin{array}{c}168 \\
(88,0)\end{array}$ & $\begin{array}{c}180 \\
(94,2)\end{array}$ & 3,9 & 7,0 & 3,2 & $<0,01$ \\
\hline $\begin{array}{l}\text { Việc tìm sự giúp đỡ } \\
\text { ngay cho viểc sữ dung } \\
\text { ma túy là rẩt cấp thiê̂t }\end{array}$ & $\begin{array}{c}166 \\
(82,6)\end{array}$ & $\begin{array}{c}181 \\
(90,0)\end{array}$ & $\begin{array}{l}163 \\
(85,3)\end{array}$ & $\begin{array}{c}165 \\
(86,4)\end{array}$ & 9,0 & 1,3 & 7,7 & $<0,01$ \\
\hline $\begin{array}{l}\text { Gây ra các vấn đề đối } \\
\text { với gia đình và bạn bè }\end{array}$ & $\begin{array}{c}181 \\
(90,0)\end{array}$ & $\begin{array}{c}187 \\
(93,0)\end{array}$ & $\begin{array}{c}172 \\
(90,1)\end{array}$ & $\begin{array}{c}179 \\
(93,7)\end{array}$ & 3,3 & 4,0 & 0,7 & 0,01 \\
\hline Gây ra nhiêu rắc rối & $90(94,5)$ & $187(93,0)$ & $176(92,1)$ & $185(96,9)$ & 1,6 & 5,2 & 3,6 & $<0,01$ \\
\hline $\begin{array}{c}\text { Bạn đang mêtt mỏi với } \\
\text { những vấn đề gây ra } \\
\text { bởi ma túy }\end{array}$ & $\begin{array}{c}178 \\
(88,6)\end{array}$ & $\begin{array}{c}180 \\
(89,6)\end{array}$ & $\begin{array}{c}169 \\
(88,5)\end{array}$ & $\begin{array}{c}177 \\
(92,7)\end{array}$ & 1,1 & 4,7 & 3,6 & $<0,01$ \\
\hline $\begin{array}{l}\text { Gây ra các vấn đề khi } \\
\text { tìm kiếm hay duy trì }\end{array}$ & $\begin{array}{c}185 \\
(92,0)\end{array}$ & $\begin{array}{c}185 \\
(92,0)\end{array}$ & $\begin{array}{c}171 \\
(89,5)\end{array}$ & $\begin{array}{c}177 \\
(92,7)\end{array}$ & 0,0 & 3,6 & 3,6 & - \\
\hline
\end{tabular}




\begin{tabular}{|c|c|c|c|c|c|c|c|c|}
\hline việc làm & & & & & & & & \\
\hline $\begin{array}{l}\text { Bạn sẽ từ bỏ bạn bè } \\
\text { và không giao lưu với } \\
\text { họ để giải quyết vấn đề }\end{array}$ & $\begin{array}{c}131 \\
(65,2)\end{array}$ & $\begin{array}{c}117 \\
(58,2)\end{array}$ & $\begin{array}{c}122 \\
(63,9)\end{array}$ & $\begin{array}{c}98 \\
(51,3)\end{array}$ & 10,7 & 19,7 & 9,0 & $<0,01$ \\
\hline $\begin{array}{c}\text { Có thế bỏ ma túy mà } \\
\text { không cần bất kỳ sự } \\
\text { trợ giúp nào }\end{array}$ & $\begin{array}{c}73 \\
(36,3)\end{array}$ & $\begin{array}{c}62 \\
(30,8)\end{array}$ & $\begin{array}{c}65 \\
(34,0)\end{array}$ & $\begin{array}{c}46 \\
(24,1)\end{array}$ & 15,2 & 29,1 & 14,0 & $<0,01$ \\
\hline $\begin{array}{l}\text { Gây nên các vấn đề } \\
\text { sức khỏe của ban }\end{array}$ & $\begin{array}{c}193 \\
(96,0)\end{array}$ & $\begin{array}{c}192 \\
(95,5)\end{array}$ & $\begin{array}{c}181 \\
(94,8)\end{array}$ & $\begin{array}{c}184 \\
(96,3)\end{array}$ & 0,5 & 1,6 & 1,1 & $<0,01$ \\
\hline $\begin{array}{l}\text { Cuộc sống của ban đã } \\
\text { khồng thể kiểm soát được }\end{array}$ & $\begin{array}{c}135 \\
(67,2)\end{array}$ & $\begin{array}{c}151 \\
(75,1)\end{array}$ & $\begin{array}{c}128 \\
(67,0)\end{array}$ & $\begin{array}{c}150 \\
(78,5)\end{array}$ & 11,8 & 17,2 & 5,4 & $<0,01$ \\
\hline $\begin{array}{l}\text { Làm cuộc sống của } \\
\text { bạn trở nên tồi tệ }\end{array}$ & $\begin{array}{c}183 \\
(91,0)\end{array}$ & $\begin{array}{c}183 \\
(91,0)\end{array}$ & $\begin{array}{c}169 \\
(88,5)\end{array}$ & $\begin{array}{c}181 \\
(94,8)\end{array}$ & 0,0 & 7,1 & 7,1 & - \\
\hline Có thể dần đến cái chết & $192(95,5)$ & $194(96,5)$ & $181(94,8)$ & $188(98,4)$ & 1,0 & 3,8 & 2,8 & $<0,01$ \\
\hline $\begin{array}{l}\text { Muốn quay laai cuộc } \\
\text { sống bình thướng }\end{array}$ & $\begin{array}{c}197 \\
(98,0) \\
\end{array}$ & $\begin{array}{c}197 \\
(98,0) \\
\end{array}$ & $\begin{array}{c}186 \\
(97,4) \\
\end{array}$ & $\begin{array}{c}186 \\
(97,4) \\
\end{array}$ & 0,0 & 0,0 & 0,0 & - \\
\hline
\end{tabular}

Can thiệp có tác động lên hâu hết các khía cạnh tâm trạng thường gặp của người NCMT khi muốn thay đổi $(p<0,05)$ ngoại trừ gây ra các vấn đề khi tìm kiếm/duy trì việc làm, làm cuộc sống trở nên tồi tệ và có thể dẩn đến cái chết.

\section{BÀN LUẬN}

Nghiên cứu của chúng tôi tương đồng với nghiên cứu của tác giả Vivian F. Go tại Thái Nguyên (2016) với tỳ lệ đối tượng tốt nghiệp trung học chiếm tới $66,4 \%$. Tỷ lệ người nhiếm HIV thất nghiệp chỉ chiếm khoảng $10 \%$, còn lại phần lớn đối tượng đều có việc làm và chủ yếu làm những công việc toàn thời gian [5]. Tại Hoa Kỳ (2012), tỷ lệ người nhiễm HIV bị thất nghiệp cao hơn đáng kể với trên $60 \%$ đối tượng không có việc làm [6]. Kết quả cho thấy, tỷ lệ người NCMT hay nhiếm HIV tại Việt Nam ít rơi vào tình trạng thất nghiệp hơn một số quốc gia khác dù đặc điểm chung của nhóm đối tượng này là trình độ học vấn không cao. Điều này có thể do Việt Nam là quốc gia đang phát triển, nông nghiệp vẫn đóng vai trò quan trọng, lao động chân tay còn phổ biến, đây là những công việc không yêu cầu cao về trình độ học vấn. Vì vậy, người NCMT hay nhiễm HIV tại Việt Nam vẫn có thể tham gia hoạt động kinh tế dù mức thu nhập chưa cao.

Theo Điều tra đánh giá Các mục tiêu trẻ em và phụ nữ (2011), tỷ lệ phụ nữ từng nghe về AIDS chấp nhận 4 hoàn cảnh: không giữ bí mật, sẵn lòng chăm sóc cho thành viên gia đình, chấp nhận cô giáo nhiễm HIV nhưng không ốm vẫn nên được phép tiếp tục giảng dạy và chấp nhận việc mua rau tươi từ người bán hàng nhiểm HIV chiếm 28,9\% [7]. Trong đó, khu vực Đồng bằng sông Hồng và Trung du miền núi phía Bắc là khu vực có quan điểm chấp nhận cao với 4 hoàn cảnh trên, chiếm lần lượt $37,2 \%$ và $36,3 \%$ [7]. Trong nghiên cứu của chúng tôi, trước khi tiến hành can thiệp nhóm can thiệp có dưới $30 \%$ người NCMT cho rằng họ được mọi người sẵn lòng chấp nhận, mọi người cho rằng người NCMT đáng tin cậy; từ dưới $10 \%$ NCMT cảm thấy mọi người sẵn lòng chấp nhận một người sử dụng ma túy là giáo viên $(10,9 \%)$, thuê họ chăm sóc con cái $(8,5 \%)$. Thực tế cho thây rằng, các cảm giác tiêu cực của người NCMT có dấu hiệu tăng lên đáng kể sau 12 tháng can thiệp ở cả hai nhóm can thiệp và đối chứng. Điều này có thế do can thiệp chưa thực sự tác động nhiều đến cải thiện suy nghĩ, tình cảm, cảm xúc của đối tượng. Người NCMT không phải là đối tượng nhận được can thiệp trực tiếp mà chỉ tham gia để đánh giá hiệu quả can thiệp. Vì vậy, chúng tôi đề xuất nghiên cứu tiếp theo tiến hành can thiệp trực tiếp trên người NCMT để đánh giá hiệu quả can thiệp về cảm giác của đối tượng rõ ràng hơn.

Can thiệp có tác động lên hầu hết các khía cạnh tâm trạng thường gặp của người NCMT khi muốn thay đởi $(p<0,05)$ ngoại trừ gây ra các vấn đề khi tìm kiếm/duy trì việc làm, làm cuộc sống trở nên tồi tệ và có thể dẫn đến cái chết. Chương trình can thiệp đã giúp đối tượng hiểu rõ hơn tác hại mà việc sử dụng ma túy ảnh hưởng đến cuộc sônng như liên quan đến pháp luật, ảnh hưởng đến suy nghĩ và thực hiện công việc, vấn đề với bạn bè, gia đình, có thể dẫn đến cái chết và các rắc rối khác. Nghiên cứu của tác giả Trịnh Thị Sang (2012) tại tỉnh Bắc Giang tương đồng với nghiên cứu của chúng tôi khi cho thấy, sau can thiệp những người NCMT đã tự tôn trọng mình hơn, tin tưởng vào hoạt động của câu lạc bộ, đồng đẳng viên và thực hiện các hành vi tiêm chích an toàn và tình dục an toàn để bảo vệ bản thân khỏi nguy cơ lây nhiễm HIV [8]. 


\section{KẾT LUÂ̂N}

Can thiệp có tác động đến cảm giác thường gặp của người nghiện chích ma túy và có hiệu quả tích cực giúp đối tượng nhận ra các vấn đề tiêu cực mà việc sử dụng ma túy có thể ảnh hưởng đến cuộc sống $(p<0,05)$.

\section{TÀI LIÊUU THAM KHẢO}

1. Bộ Y tế, Báo cáo Kết quả công tác phòng, chống HIV/AIDS năm 2019 và nhiệm vụ trọng tâm năm 2020, 2020.

2. Bộ Y tế, USAID, PEFFAR, FHI 360, Đánh giá hiệu quả của chương trình thí điểm điều trị nghiện các chất thuốc phiện bằng methadone, 2014.

3. Bach Xuan Tran, Anh Kim Dang, Nu Thi Truong et al, "Depression and Quality of Life among Patients Living with HIV/AIDS in the Era of Universal Treatment Access in Vietnam," Int J Environ Res Public Health, 2018.
4. Nguyễn Thị Thắm, "Nghiên cứu thực trạng và giải pháp can thiêp bỏ điêu tri Methadone ở bênh nhân nghiện các chất dạng thuốc phiện tại Hải Phòng, 2014-2016," Luận văn Tiến sĩ Ỳ tế công cộng, Trường Đại học Y Dược Hải Phòng, 2018.

5. Go V.F., Latkin C., Le Minh N. et al, "Variations in the role of social support on disclosure among newly diagnosed HIV-infected people who inject drugs in Vietnam," AIDS Behav, 2016.

6. Przybyla S.M., Golin C.E., Widman L. et al, "Serostatus disclosure to sexual partners among people living with HIV: examining the roles of partner characteristics and stigma," AIDS Care, 2013.

7. Tổng cực thống kê, UNICEF, ÚNFPA, MICS Việt Nam (Điều tra đánh giá Các mục tiêu trẻ em và phụ nữ), 2011.

8. Trinh Thị Sang, "Đánh giá hiêu quả can thiêp tiếp cận động đồng trong nhóm người nghiển chích ma tủy tại thành phố Bắc Giang tỉnh Bằc Giang năm 200خ-2010," Luận án Tiến sĩ, Trường Đại học Y tế công cộng, 2012.

\title{
PHẪU THUÂT LICHTENSTEIN SỬ DỤNG LƯỚI NHÂN TẠO TƯ DÍNH PARIETEX PROGRIP (COVIDIEN) ĐIỀU TRI THOÁT VI BẸN TẠI TỈNH THANH HÓA
}

\author{
Lưu Anh Đức ${ }^{1}$, Đỗ Trường Sơn ${ }^{2}$, \\ Trịnh Ngọc Thắng1, Lê Văn Minh ${ }^{3}$, Nguyễn Anh Tuấn ${ }^{3}$
}

\section{TÓM TẮT}

Mục tiêu: Mô tả kỹ thuật và đánh giá kết quả sớm của phẫu thuật Lichtenstein sử dụng lưới nhân tạo tự dính Parietex Progrip (Covidien) điều trị thoát vị bẹn tại tỉnh Thanh Hóa. Đối tượng và phương pháp: Nghiên cứu mô tả loạt ca bểnh tiến cứu, dưa trên đề cương thống nhất cho 3 điểm nghiên cứu cùng tham gia tại địa bàn tỉnh Thanh Hóa. Mô tả các đặc điểm lâm sàng, cận lâm sàng, kỹ thuật mổ và kết quả bước đầu sau mổ. Kết quả: Từ tháng 01/2020 đến tháng 3/2021 đã có 68 bệnh nhân bị thoát vị bẹn được mổ bằng phẫu thuật Lichtenstein sử dụng lưới nhẩn tạo tự dính Parietex Progrip (Covidien). Tất cả bệnh nhân đều là nam giới, tuổi trung bình $5 \dot{3} .9 \pm 17.00$ tuổi (16-89), BMI: 21.2 1.79 (16.9 27.3), 67 TVB là nguyên phát, chỉ có 1 ca là tái phát sau mổ Bassini. Tất cả đều được mổ dưới gây tê tủy sống. Đường rạch da chủ yếu theo đường phân giác của góc tam giác bẹn từ củ mu $(97,1 \%)$, chỉ có 1 trường hợp dùng đường rạch ngang gốc bìu. Độ dài đường rạch da trung bình $6.9 \pm 1,71 \mathrm{~cm}(6-18)$; thời gian mổ: $54,7 \pm 7,74$ phút $(25-80)$; thời gian phẫu

${ }^{1}$ Bệnh viện 71 Trung ương

${ }^{2}$ Dại họ Y Hà nọi

${ }^{3}$ Bênh viên $Đ K$ Tỉnh Thanh Hóa

Chịu trách nhiệm chính: Lưu Anh Đức

Email: anhduc10071972@gmail.com

Ngày nhận bài: 22.2.2021

Ngày phản biên khoa họ: 2.4.2021

Ngày duyệt bài: 12.4 .2021 tích ống ben: $20,4 \pm 16,68$ phút $(10-50)$; thời gian đặt tấm lưới: $6,0 \pm 1,09$ phút (5-10). Không có tai biến trong lúc mổ, có 11 trường hợp sau mổ bị bí tiểu (16,2\%). Số ngày đau sau mổ: $6.2 \pm 0.71$ ngày (4-7), ơ mức nhe hoặc trung bình. Kết quả kiểm tra 1 tháng sau mổ: tốt/bình thường 55BN $(80.9 \%)$, cảm giác căng dày vùng bẹn 7BN $(10,3 \%)$. Kết luận: Phẫu thuật Lichtenstein điều trị thoát vị bẹn bằng tấm lưới tư dính Parietex Progrip Covidien là an toàn, hiệu quả và ít đau sau mô.

Tư khóa: Thoát vị bẹn, phẫu thuật tạo hình thoát vị, tấm lưới tự dính Parietex Progrip (Covidien).

\section{SUMMARY}

SELF-GRIPPING MESHES PARIETEX PROGRIP (COVIDIEN) FOR LICHTENSTEIN INGUINAL HERNIA REPAIR AT HOSPITALS OF THANH HOA PROVINCE

Objective: To describe technics and evaluate outcomes of using self-gripping mesh Parietex Progrip (Covidien) for Lichtenstein inguinal hernia repair at hospitals of Thanh Hóa province. Patients and methods: A pro-descriptive cases study based on patient suffered inguinal hernia and underwent selfgripping meshes Parietex Progrip (Covidien) for Lichtenstein repair at hospitals of Thanh Hóa province. Surgical technics were described as well as clinical, para-clinical features and primary results also reported. Results: From Jan. 2020 to Mars 2021, 68 patients with inguinal hernia underwent Lichtenstein repair using self-gripping meshes Parietex Progrip 